\title{
DEFINICIÓN DEL CONCEPTO DE NOMBRE A TRAVÉS DE LA GRAMÁTICA CENTRADA EN EL VERBO O GRAMÁTICA VIVA

\author{
A Fino y Bello
}

\author{
Norma Corrales-Martin \\ Maritza Bell-Corrales
}

\begin{abstract}
RESUMEN
Al estudiar las gramáticas modernas del español, sean de carácter estructuralista, funcionalista o generativista se puede notar que los conceptos de las partes de la oración o categorías gramaticales y particularmente el concepto de nombre, aún obedecen al paradigma tradicional centrado en el nombre- sujeto definido por Nebrija, Bello y Cuervo y la Real Academia desde 1771. A la luz de una gramática centrada en el verbo, la gramática verbal o Gramática Viva, y usando un corpus compuesto de 50 canciones populares hispanas, expresión de la lengua en acción, escogidas por su riqueza gramatical y semántica, intentamos demostrar que el nombre y otras categorías gramaticales pueden ser definidos de manera más productiva. Nuestro objetivo es proponer un paradigma que tomando al verbo como categoría esencial permite diferenciar morfo-sintácticamente entre: a) El sustantivo, el adjetivo y el adverbio como categorías primarias, es decir, nombres; b) el adjetivo como categoría secundaria calificando y cuantificando nombres sustantivos; c) el adverbio como categoría secundaria cuantificando e intensificando nombres sustantivos, nombres adjetivos y nombres adverbios; y d) el adverbio como categoría terciaria intensificando adjetivos y adverbios. Palabras clave: Gramática centrada en el verbo; categorías gramaticales; nombre sustantivo; nombre adjetivo; nombre adverbio.
\end{abstract}

\begin{abstract}
When studying Spanish grammars of different character, structural, functionalist or generativist, it can be noticed that the concept of parts of the sentence or grammatical categories, and particularly the concept of noun, still follows the traditional paradigm centered in the noun- subject defined by Nebrija, Bello and Cuervo and the Real Academia since 1771. Using a grammar centered in the verb, verbal grammar or Gramática Viva, and using a corpus of 50 popular Hispanic songs, expression of language in action, chosen for their grammatical and semantic richness, we intent to demonstrate that noun and other grammatical categories can be defined in a more productive manner. Our objective is to propose a paradigm which, taking the verb as the essential category, allows to differentiate morpho-syntactically between: a) Substantive, adjective and adverb as primary categories, that is, nouns; b) Adjective as a secondary category qualifying and quantifying substantive nouns; c) Adverb as a secondary category quantifying and intensifying substantive nouns, adjective nouns, and adverb nouns; and d) Adverb as a tertiary category intensifying adjectives and adverbs.
\end{abstract}

Key words: Verb centered grammar; grammatical categories; noun substantive; noun adjective; noun adverb.

Ph. D.Norma Corrales Martin. Profesora de español. Temple University, Philadelphia, PA Correo electrónico: ncm@temple.edu

Ph. D. Maritza Bell-Corrales. Profesora de español y lingüística. Macon College

Correo electrónico: maritza.bellcorrales@maconstate.edu

Recepción: 11- 03- 2010

Aceptación: 24- 05- 2010 


\section{Introducción}

Al estudiar las gramáticas modernas del español, sean de carácter estructuralista (Ofelia Kovacci, 1986), funcionalista (Alarcos Llorach 1973; S. Gutiérrez Ordoñez 1997) o generativista (Bosque \& Demonte 1999) se puede notar que los conceptos de las partes de la oración o categorías gramaticales y particularmente el concepto de nombre, aún obedecen al paradigma tradicional centrado en el nombre- sujeto definido por Nebrija (1492), Bello y Cuervo (1847) y la Real Academia desde 1771.

A la luz de una gramática centrada en el verbo, la gramática verbal o Gramática Viva (Corrales-Martin, 2004 [2006]), y usando un corpus compuesto de 50 canciones populares hispanas, expresión de la lengua en acción, escogidas por su riqueza gramatical y semántica, intentamos demostrar que el nombre y otras categorías gramaticales pueden ser definidos de manera más productiva.

Gramática Viva (2004 [2006]) es el resultado de una extensión original al español de los presupuestos de la Gramática de Caso (Fillmore, 1968) y la Teoría de los Constituyentes (Bloomfield 1933; Wells 1958; Hockett 1958); Gramática Viva está basada en el conocimiento aportado por los grandes maestros del español, y es corroborada por la permanente investigación sobre un extenso corpus de canciones y otros textos, y acreditada por publicaciones y por su entusiasta acogida en el aula de clase.

Nuestro objetivo es proponer un paradigma que tomando al verbo como categoría esencial permite diferenciar morfo-sintácticamente entre:

a) el sustantivo, el adjetivo y el adverbio como categorías primarias, es decir, nombres;

b) el adjetivo como categoría secundaria calificando y cuantificando nombres sustantivos;

c) el adverbio como categoría secundaria cuantificando e intensificando nombres sustantivos, nombres adjetivos y nombres adverbios; y

d) el adverbio como categoría terciaria intensificando adjetivos y adverbios.

Profundizaremos este análisis en el apartado número 5.

\section{Revisión de literatura}

\subsection{El concepto conocido de nombre sustantivo y nombre adjetivo.}

El Diccionario de la Real Academia (DRAE) define el nombre sustantivo por poseer género, por recibir determinantes y por su función como sujeto de la oración; define el nombre adjetivo por calificar o determinar al sustantivo; y los nombres en general por poder funcionar como sujeto de la oración.

\footnotetext{
nombre. (Del lat. nomen, -inis)

m. Palabra que designa o identifica seres animados e inanimados; p.ej., hombre, casa, virtud.

m. Gram. Clase de palabras con género inherente que puede funcionar, sola o con algún determinante, como sujeto de la oración.

m. Gram. Tradicionalmente, categoría de palabras que comprende el nombre sustantivo y el nombre adjetivo.

adjetivo. m. Gram. adjetivo (II que califica o determina al sustantivo).

$\sim$ sustantivo. m. Gram. nombre (Il clase de palabras que puede funcionar como sujeto de la oración).
}

En cuanto al adjetivo, Luis A. Cuadrado en su artículo, La caracterización del adjetivo en la GRAE, el Esbozo y la Gramática de E. Alarcos Llorach (1999) pone de presente las variaciones que este concepto ha tenido a través del tiempo. 
Es de notar que no se diferencia categorialmente en ninguna de estas gramáticas entre la función del adjetivo como modificador del sustantivo (la mansa oveja) y modificador del sustantivo y del verbo al mismo tiempo (Ella parecía seria). En el concepto de adjetivo del DRA, se nota que adjetivo y nombre adjetivo aparecen indiferenciados:

adjetivo (Del lat. adiectīvus)

Adj. Gram. Que califica y determina al sustantivo. Nombre adjetivo, oración adjetiva.

\subsection{El concepto de adverbio en Bello, el DRA y otros autores}

El concepto de adverbio desde Nebrija (1492) y Bello (1964) hasta nuestros días ha sido debatido en la literatura, pero las definiciones son similares hasta hoy. Cuervo, en su nota 8 a la gramática de Bello (1967: 422), considera la significación absoluta de cada palabra, sus formas y sus funciones u oficios en la frase para dividirlas en clases que se llaman partes de la oración. Bello, atendiendo a la clasificación de las palabras según su oficio en el razonamiento, dice que el adverbio es una parte de la oración que:

[...] modifica al verbo y al adjetivo: al verbo, v. gr.; corre aprisa, vienen despacio, escribe elegantemente; al adjetivo, como en una lección bien aprendida, una carta mal escrita... Sucede también que un adverbio modifica a otro, como en estas proposiciones: el ave volaba muy aceleradamente, la función terminó demasiado tarde. Nótese la graduación de modificaciones: demasiado modifica a tarde, y tarde a terminó; además terminó y volaba son, como atributos, verdaderos modificativos de los sujetos la función, el ave. (1967: 41)

Bello define los adverbios como una clase de palabras que modifican al verbo y al adjetivo, como vienen despacio, una lección bien aprendida, y también a otro adverbio: la función terminó demasiado tarde. Bello llama adverbio a esta palabra, modifique bien al verbo, ya al adjetivo, e independientemente de la gradación de significaciones. Nótese al final, la definición de verbo como modificador del sujeto, como un simple atributo del nombresujeto, que es para Bello la categoría esencial.

La Real Academia Española en el Esbozo de una Nueva Gramática de la Lengua Española (1973), ciento cincuenta años más tarde, no dedica ningún capítulo al adverbio como sí lo hace a otras partes de la oración. El DRAE lo define así:

adverbio. (del lat. adverb̆̌um). m. Gram. Palabra invariable cuya función consiste en complementar la significación del verbo, de un adjetivo, de otro adverbio, y de ciertas secuencias. Hay adverbios de lugar, como aquí, delante, lejos; de tiempo, como hoy, mientras, nunca; de modo, como bien, despacio, fácilmente; de cantidad o grado, como bastante, mucho, muy; de orden, como primeramente; de afirmación, como sí; de negación, como no; de duda o dubitativos, como acaso; de adición, como además, incluso, también; de exclusión, como exclusive, salvo, tampoco. Algunos pertenecen a varias clases.

m. Gram. Los adverbios como, cuando, cuanto y donde pueden funcionar como relativos correspondientes a los adverbios demostrativos así, según, tal, entonces, ahora, tan, tanto, aquí, allí, etc.; pueden tener antecedente expreso o implícito; p. ej., la ciudad donde nací; iré donde tú vayas.

m. Gram. Pueden también funcionar como interrogativos o exclamativos y en este caso se escriben con acento. ¿Cómo estás? ¡Cuánto lo siento!

rdemostrativo. m. Gram. El que identifica lugar, modo o tiempo; p. ej., aquí, así, ahora.

Esta definición de adverbio es adecuada: el adverbio es invariable y complementa la significación de otras palabras, pero nuevamente no se hace diferencia entre la función adverbial, ejercida sobre el adjetivo u otro adverbio, y la función nominal, ejercida en su relación directa con el verbo. 
Pedro Carbonero Cano (1971) en su artículo Criterios para una categorización funcional de los adverbios presenta un estudio bastante exhaustivo sobre los problemas que han discutido los gramáticos a través de los tiempos para definir al adverbio y concluye deduciendo que el adverbio es una clase de palabras de características heterogéneas que puede modificar al verbo, al adjetivo a otro adverbio o a una oración entera, por lo cual se le debe considerar como una categoría de rango terciario, que afecta primordialmente al sintagma verbal. Carbonero Caro considera al sustantivo en un rango primario, y tanto al adjetivo como al verbo en un rango secundario en el sentido de que inciden sobre el sustantivo que es primario. Según Carbonero Cano, entonces queda el adverbio como la categoría para incidir sobre las de rango secundario (verbo y adjetivo). Vemos que el sustantivo es la categoría primaria según este autor.

María del Carmen García Tejera (1984) en un artículo sobre el adverbio en la tradición gramatical española también estipula la complejidad sintáctica del adverbio. García Tejera sugiere que esta complejidad nace de una enorme heterogeneidad que abarca tanto la diversa procedencia de los adverbios como sus formas, sus funciones e incluso los diferentes matices que presenta su significación. Añade que durante mucho tiempo el adverbio fue considerado sólo como modificador verbal y que para definir más claramente al adverbio, la mayoría de los gramáticos lo comparan con el adjetivo diciendo que el adverbio es al verbo lo que el adjetivo es al sustantivo. Al final del artículo, la autora concluye que las teorías de los gramáticos hasta finales del siglo XIX constituyen una base sólida en que teorías más modernas se apoyan. Sin embargo, García Tejera no arroja mucha luz sobre cuál ha sido la influencia de estas teorías sobre el adverbio en la lingüística reciente.

Las definiciones de adverbio presentadas prevalecen en las gramáticas actuales del

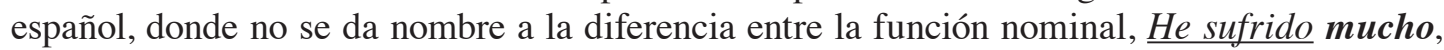
y la función adverbial, Te quiero mucho más, y no se anota que algunos como muy están casi siempre en función adverbial.

María Ángeles Martínez (1986) en su artículo, Sustantivo, adjetivo y adverbio: Caracterización funcional, propone que existe una categoría nominal: el nombre, el cual engloba tres tipos diferentes de manifestación, el sustantivo, el adjetivo y el adverbio, porque los tres poseen la capacidad de actuar como adyacentes verbales o como núcleos nominales en su propio grupo sintagmático. La propuesta de Martínez coincide con la presente en considerar sustantivo, adjetivo y adverbio como nombres, pero a nuestro parecer, es necesario diferenciar entre nombre adjetivo y nombre adverbio como categorías primarias, adjetivo como categoría secundaria y adverbio como categoría secundaria o terciaria.

María Pilar Garcés en su artículo, Caracterización de los adjetivos en función adverbial en español (2001) estudia formas adverbiales que se crean a través de la inmovilización de los morfemas de género y número del adjetivo correspondiente, adoptando la expresión propia del masculino singular. Se demuestra que es bastante común adverbializar el adjetivo en español, de lo cual encontramos ejemplos en el corpus estudiado (Sección 4.3.2). También presentaremos ejemplos donde diferentes tipos de palabras se inmovilizan para constituir expresiones adverbiales: a las buenas, poco a poco en la sección 4.3.

\section{Preguntas sobre el concepto conocido de nombre}

\section{Cuervo en las notas (1964: 422) considera que Bello}

[...] aliando la clasificación de los oficios con la de las formas (aunque sin mencionar aquí este elemento) ha establecido una clasificación que abarca la mayoría de los casos y, lo que vale más, ha dado idea clara de la estructura psicológica y gramatical de la oración y proporcionado instrumento precioso para analizar y discriminar los diversos oficios que puede desempeñar un mismo término. 
Bello definió el carácter del nombre semánticamente, porque envuelve manifiestamente la idea de cosa o colección de cosas, lugares, pensamientos e ideas; sintácticamente, por su función como sujeto y porque sirve de complemento con preposición o sin ella; morfológicamente, porque es modificado por adjetivos y complementos y porque el nombre tiene número y género (Bello 1964: 98).

A través de ejemplos provenientes del material estudiado, mostramos a continuación que las características del nombre descritas por Bello pueden ser compartidas por adjetivos y adverbios. ¿Sería conveniente entonces llamarlos nombres? Creemos que sí.

En los ejemplos presentados, el verbo estará subrayado y los constituyentes que nos interesan entre corchetes [ ]; en cursiva aparecen los núcleos del constituyente, a los cuales, desde ya, llamamos 'nombres'.

\subsection{Semánticamente, el nombre envuelve manifiestamente la idea de cosa o colección de cosas, lugares, pensamientos e ideas}

\begin{tabular}{|c|c|c|}
\hline Nombre sustantivo & Nombre adjetivo & Nombre adverbio \\
\hline [El padre] la busca afanosamente & $\begin{array}{l}\underline{\text { Es }[\text { un vago }]} \\
\underline{\text { Cuida }[\text { lo tuyo }]} \\
{[\text { La más chiquita }] \underline{\text { tuvo amores }}}\end{array}$ & $\begin{array}{l}\text { [Aquí] tenei' a tu Chiche en temple } \\
\text { El que espera [lo mucho], espera } \\
\text { [lo poco] }\end{array}$ \\
\hline
\end{tabular}

Dice Bello que el nombre (n-) sustantivo se refiere a un ser, ente o idea; pero también el adjetivo nombra el ser, por su cualidad, y el adverbio se refiere a un ENTE modo, cantidad, tiempo o espacio. ¿Los nombramos n-adjetivo y n-adverbio? Creemos que sí.

\subsection{Morfológicamente, el nombre es modificado por adjetivos (agregamos adverbios) y complementos}

\begin{tabular}{|c|c|c|}
\hline Nombre sustantivo & Nombre adjetivo & Nombre adverbio \\
\hline $\begin{array}{l}{[\text { La cándida niña }<\text { de }>\text { la sociedad] }} \\
\text { se ha fugado } \\
\text { [Sólo mi madre] me comprende a } \\
\text { mí }\end{array}$ & $\begin{array}{l}{[\text { La gorda }] \text { bailando }} \\
{[\text { Esa malagradecida] yo pensaba }} \\
\text { que... } \\
\text { Paso a contar }[\text { lo siguiente }] \\
\text { Eres [muy grande] } \\
\text { La vida es [algo dura] } \\
\text { ¿Qué cheverón! }\end{array}$ & $\begin{array}{l}\text { Nada más se oye este cantar, [muy } \\
\text { bien] } \\
\text { Bésame [un poquito] } \\
\text { (poquito se refiere al verbo; es } \\
\text { invariable) }\end{array}$ \\
\hline
\end{tabular}

Vemos arriba que el adjetivo y el adverbio pueden recibir los modificadores del sustantivo, pero también tienen modificadores propios, como el artículo neutro 'lo', lo tuyo, lo mucho, o el adverbio, la más chiquita.

\subsection{Sintácticamente, el nombre sirve de sujeto}

\begin{tabular}{|c|c|c|}
\hline Nombre sustantivo & Nombre adjetivo & Nombre adverbio \\
\hline $\begin{array}{l}\text { [El padre] la busca } \\
\text { afanosamente }\end{array}$ & $\begin{array}{l}{[\text { Mi viejo }] \text { dice }} \\
\text { Ay, }[\text { negra }] \text { búscate un } \\
\text { catéter (vocativo) }\end{array}$ & [Aquí] no es mesón \\
\hline
\end{tabular}


Vemos que también el adjetivo y el adverbio pueden actuar como sujetos y complementos. ¿Los nombramos n-adjetivo-sustantivo y n-adverbio-sustantivo en lugar de nombrarlos sustantivados? Creemos que sí.

\subsection{Sintácticamente, el nombre sirve de complemento con preposición o sin ella}

\begin{tabular}{|c|c|c|}
\hline Nombre sustantivo & Nombre adjetivo & Nombre adverbio \\
\hline $\begin{array}{l}\text { De nada sirvieron [regalos, ni } \\
\text { viajes ni bodas] } \\
\text { Salí a comprarte [una cadena que] } \\
\text { te llegue [a la rodilla] }\end{array}$ & $\begin{array}{l}\text { Nada es útil [para esta inútil] } \\
\text { No vayas a olvidar [a este negrito] } \\
\text { No le pegue [a ajena] }\end{array}$ & $\begin{array}{l}\text { Yo [mañana mismo] me caso } \\
\text { Mira [hacia arriba] }\end{array}$ \\
\hline
\end{tabular}

Dice Bello (1964: 42) que no hay preposición sin término. ¿Es posible llamar nombre al término de preposición, sea sustantivo, adjetivo o adverbio como en los ejemplos arriba? Creemos que sí.

\subsection{Morfológicamente, el nombre tiene número y género (Bello 1964) y el adverbio no}

\begin{tabular}{|l|l|l|}
\hline Nombre sustantivo & Nombre adjetivo & Nombre adverbio \\
\hline$\underline{\text { Quiero matar [un capricho] }}$ & Las palmas son [más altas] & Yo [mañana mismo] me caso \\
\hline
\end{tabular}

Interesa sobre manera el tema del género y número del nombre. Sabemos que el n-sustantivo los tiene, que el n-adjetivo tiene género y número pues concuerda con un n-sustantivo, y que el adverbio se diferencia de los dos anteriores porque no los tiene. Sin embargo, algunos nombres que se refieren al tiempo del verbo (día, mañana, tarde, noche, vez) a veces tienen número y otras no lo tienen. ¿Pertenecen a diferentes categorías gramaticales si tienen número y género, [la mañana] iba de gris, y si reciben o no determinantes, [todas las mañanas], [mañana mismo]? Creemos que sí.

Tomando como base esta información podemos concluir que el n-adjetivo y el n-adverbio comparten con el n-sustantivo de manera restringida todas las funciones estudiadas por Bello. Como el nombre sustantivo, completan la significación del verbo con el objetivo humano de nombrar la realidad para pensar o comunicar. Sin embargo, si tomamos como paradigma la gramática centrada en el verbo, ¿es posible estudiar las características y funciones específicas del nombre de manera productiva, usando un solo criterio, el ser núcleo del constituyente en una relación particular de caso con el verbo?

Esta pregunta es nuestra hipótesis de investigación y a responderla dedicamos nuestro análisis. A continuación presentamos como marco teórico los presupuestos de la gramática centrada en el verbo, para luego aplicarlos al corpus.

\section{Marco teórico: La gramática centrada en el verbo}

El criterio de clasificación que proponemos considera al verbo como centro de la oración (Fillmore 1968) y utiliza el concepto de constituyente (Bloomfield 1933; Wells 1958; Hockett 1958) para delimitar los casos, entendidos como relaciones semánticas que las palabras establecen con la acción expresada por el verbo. 
Gramática viva (2004 [2006]) no usa los conceptos de sujeto, predicado o atributo, sino que plantea que todos los casos están a igual nivel de relación con el verbo. Vamos a presentar el paradigma de análisis sugerido en Gramática viva $(G V)$.

$G V$ define oración en los diferentes niveles del discurso, así: ${ }^{1}$

$\begin{array}{ll}\text { Semánticamente: } & \mathrm{O} \rightarrow \text { modalidad } \underline{\text { acción }}+\left[\mathrm{caso}_{\mathrm{X}}\right] \\ \text { Sintácticamente: } & \mathrm{O} \rightarrow \text { modalidad } \underline{\text { verbo }}+[\text { constituyente] } \\ \text { Morfológicamente: } & \mathrm{O} \rightarrow \text { modalidad } \underline{\text { verbo }}+[\text { nombre] }\end{array}$

La modalidad de la oración indica la intención del hablante de aseverar, afirmar, negar, dudar, condicionar y se realiza comúnmente a través de la categoría n-adverbio (sí, no, quizás, etc.) y los rasgos supra-segmentales.

En el nivel semántico, la acción enunciada o tácita se acompaña de otras palabras que informan el quién, qué, a quién, cómo, cuándo, dónde, etc. de la acción, es decir, que establecen con la acción una relación semántica de caso, a saber, agente y paciente persona y cosa, modal, tiempo, espacio, etc. de la acción expresada por el verbo en el nivel sintáctico.

En el nivel sintáctico, cada verbo conjugado (simple, compuesto o perifrástico) se acompaña de constituyentes, palabras que forman una unidad de sentido alrededor de un núcleo protonominal. Verbo es un verbo conjugado y verbal es una forma no conjugada del verbo, infinitivo (el nombre del verbo), gerundio (la acción del verbo) y participio (el estado del verbo $)^{2}$. El verbo y el verbal pueden constituir perífrasis. El núcleo del constituyente pertenece al nivel morfológico.

En el nivel morfológico del discurso, el núcleo del constituyente es un nombre o una palabra que hace su oficio, introducido, modificado y/o complementado o no por otras palabras de igual o menor categoría.

Observemos los tres niveles en el ejemplo 1:

\begin{tabular}{|c|c|c|c|c|c|}
\hline $\begin{array}{l}{[\mathrm{Ya}]} \\
\text { cuándo } \\
\text { tiempo }\end{array}$ & $\begin{array}{l}\text { [tú] } \\
\text { quién } \\
\text { agente } \\
\text { persona }\end{array}$ & $\begin{array}{l}\text { no } \\
\text { mod }\end{array}$ & $\begin{array}{l}{[\text { me }]} \\
\text { a quién } \\
\text { paciente } \\
\text { persona }\end{array}$ & $\begin{array}{l}\frac{d a s}{\text { acción }} \\
\text { verbo }\end{array}$ & $\begin{array}{l}\text { [el mismo trato suavecito } \\
\text { qué } \\
\text { paciente } \\
\text { cosa }\end{array}$ \\
\hline $\mathrm{adv}]$ & [pron] & & [pron] & $\mathrm{v}$ & [art-adj- nsust-adjetivo] \\
\hline
\end{tabular}

El verbal puede también estar acompañado de nombres que establecen relación de caso con él, pero en esta estructura el verbal no es núcleo de la oración como en las perífrasis, sino núcleo del constituyente:

$\begin{array}{lcccc}\text { (Nosotros) } & \text { Tratemos de arreglar } & \text { [a las buenas] } & \text { [pa' quedar[nos] } & \text { [juntos]] } \\ \text { quién } & \text { acción } & \text { cómo } & \text { para qué quién } & \text { cómo } \\ \text { ag tácito } & \text { verbo } & \text { modal } \mathrm{v} 1 & \text { finalidad v agente vbl } & \text { modal vbl } \\ \text { [pronombre] } & \mathrm{v}<\mathrm{de}>\mathrm{vbl} & {[\text { prep-art-nadj] }} & \text { [prep-verbal[pron] } & \text { [nadj]] }\end{array}$

Si hay más de un verbo conjugado en la oración es importante definir su importancia: el verbo ${ }_{1}$ no pertenece a ningún constituyente, el verbo ${ }_{2}$ aparece dentro de un constituyente. El verbo $_{2}$, incluso en su función relativa, no forma oración sino constituyente o frase.

Para $G V$, el verbo es la categoría esencial y el nombre (n-) es una categoría primaria que funciona como núcleo de constituyente del verbo. El núcleo del constituyente nominal es un n-sustantivo, n-adjetivo o n-adverbio, o un pronombre que se relaciona con el verbo en una determinada relación de caso. 
Los constituyentes en que el núcleo es un n-adjetivo o n-adverbio serán estudiados, para determinar las semejanzas y diferencias entre ellos y el n-sustantivo, desde el punto de vista de la relación de caso con el verbo y los modificadores con los cuales se acompañan. A los conceptos de n-adjetivo y n-adverbio contrastamos los de adjetivo y adverbio. Cincuenta canciones han sido analizadas para establecer diferencias o semejanzas entre estas categorías, de las cuales resultaron 494 tokens.

Vale dejar dicho que el nombre sustantivo es el más común y que como núcleo del constituyente (incluyendo los pronombres) establece con el verbo todas las posibles relaciones de caso determinadas en Gramática Viva (Corrales-Martin, 2004 [2006]), a saber:

a. agente persona y cosa: Yo llegué a San Juan; Ya se me cayó la roncha

b. experimentador: Ya se me cayó la roncha

c. vocativo: Óigame, compai Pascual

d. paciente persona y cosa: Óigame, compai, Doy este gusto a mis pies

e. modal: No puedo vivir sin ellos

f. cantidad: Lo que vende vale un millón

g. tiempo: Adoro la tarde <en> que nos vimos

h. espacio: Ahora escribo en un papel; Yo llegué a San Juan; Me trae [por la izquierda]

i. compañía: Ahora yo me codeo con Eddy y con Rafael

j. instrumento: Ahora mis pies yo los calzo con zapatos de Glacer

k. razón: Te doy las gracias por perdonarme

1. finalidad: $\underline{\text { Canto }}$ para olvidar

Esto dicho, el nombre sustantivo, extensamente estudiado a través de los siglos, será en adelante sólo objeto tangencial del actual estudio.

\section{Presentación y análisis de datos}

Según nuestro análisis, el verbo es la categoría esencial y el nombre es una categoría primaria, porque se relaciona con el verbo, por sí mismo o a través de preposiciones. El nombre es siempre el núcleo de un constituyente en una cierta relación de caso con el verbo. Dentro de su constituyente, el nombre también se relaciona con otros nombres, a través de enlaces, notablemente preposiciones y conjunciones y con otros verbos, a través de enlaces, notablemente, pronombres relativos (Corrales-Martin 2008).

Así definidos los términos, este estudio ahora se referirá a las categorías primarias n-adjetivo y n-adverbio, núcleos de un constituyente en determinada relación de caso con el verbo; en contraste con las categorías secundarias adjetivo, modificador del nombre sustantivo, y adverbio, modificador del nombre; y la categoría terciaria adverbio, modificador de adjetivos y de otros adverbios. A partir de nuestra hipótesis (Sección 2) y según los ejemplos encontrados en el corpus proponemos las categorías nombre adjetivo-sustantivo, nombre adjetivo, nombre adverbio-sustantivo, nombre adverbio-adjetivo, nombre adverbio, adverbio y adjetivo. Los totales se presentan así:

\begin{tabular}{|l|l|l|l|l|l|l|l|}
\hline $\begin{array}{l}\text { Nombre } \\
\text { adjetivo- } \\
\text { sustantivo }\end{array}$ & $\begin{array}{l}\text { Nombre } \\
\text { adjetivo }\end{array}$ & Adjetivo & $\begin{array}{l}\text { Nombre } \\
\text { adverbio- } \\
\text { sustantivo }\end{array}$ & $\begin{array}{l}\text { Nombre } \\
\text { adverbio- } \\
\text { adjetivo }\end{array}$ & $\begin{array}{l}\text { Nombre } \\
\text { adverbio }\end{array}$ & Adverbio & Total \\
\hline 23 & 85 & 147 & 4 & 9 & 153 & 73 & 494 \\
\hline
\end{tabular}




\subsection{Revisión del concepto de nombre adjetivo}

En total, el n-adjetivo es núcleo de un constituyente y se relaciona con el verbo en 108 ejemplos. Sin embargo encontramos en el material diferencias en sus relaciones de caso y modificadores, que ameritan proponer las variaciones, n-adjetivo-sustantivo y n-adjetivo propiamente.

\subsubsection{Nombre adjetivo-sustantivo}

Cuando el n-adjetivo se relaciona con el verbo como casos vocativo, agente persona, paciente cosa y paciente persona, el núcleo adjetivo se caracteriza por recibir los modificadores del n-sustantivo. Sin embargo, como tiene características propias no compartidas por el n-sustantivo, lo llamamos n-adjetivo-sustantivo, en lugar de decir que está sustantivado. Las frecuencias son:

\begin{tabular}{|l|l|l|l|l|}
\hline Caso vocativo & $\begin{array}{l}\text { Caso agente } \\
\text { persona }\end{array}$ & Caso paciente cosa & $\begin{array}{l}\text { Caso paciente } \\
\text { persona }\end{array}$ & $\begin{array}{l}\text { Total } \\
\text { Casos del verbo }\end{array}$ \\
\hline 2 & 6 & 12 & 3 & 23 \\
\hline
\end{tabular}

El n-adjetivo-sustantivo fue encontrado en 23 ejemplos. Se relaciona con el verbo como vocativo en 2 ejemplos: Ay, [negra], mira, búscate un catéter; como agente persona en 6 ejemplos: [La gorda] (va) bailando; como paciente cosa en 12 ejemplos: Es [un bombón],

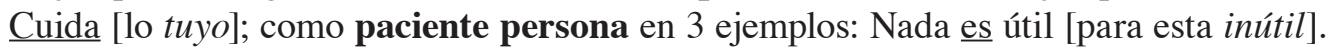

En cuanto a sus modificadores, encontramos que en estos casos el núcleo adjetivo es modificado por artículos y demostrativos, pero además, a diferencia del n-sustantivo, por el artículo neutro 'lo', el cual sirve para dar a la cualidad la condición de objeto: Paso a contar [lo siguiente], Tiene [lo bello] de aquí hasta el Magdalena.

En los ejemplos de paciente persona, este es introducido por preposición, como corresponde en este caso: No vayas a olvidar [a este negrito]. En dos ejemplos de superlativo, [La más chiquita] no estuvo chiquita para tener amores, Eres [la más bonita], es modificado por adverbio. En un ejemplo, no se relaciona con el verbo sino con el n-sustantivo a través de preposición: Para mí es [mejor] [ser dueño <de> lo más divino].

\subsubsection{Nombre adjetivo propiamente}

Se manifiesta en el caso modal. El núcleo adjetivo se refiere al verbo y al nombre al mismo tiempo; concuerda en género y número con el nombre al que se refiere, a diferencia del n-adverbio como veremos en 4.3, y se caracteriza por no recibir más modificador que el adverbio. Lo llamamos n-adjetivo a secas. Se relaciona con el verbo como caso modal en 85 ejemplos, siendo 'ser' el verbo más común, seguido por 'estar'. No consideramos al n-adjetivo atributo, sino caso modal del verbo.

\begin{tabular}{|l|l|l|l|}
\hline Caso modal & Verbo ser & Verbo estar & Otros verbos \\
\hline 85 & 33 & 19 & 33 \\
& $2 / 33$ son participio & $11 / 19$ son & $10 / 33$ son participio \\
& pasado & participio pasado & pasado \\
\hline
\end{tabular}


En 33 ejemplos, el n-adjetivo se relaciona con el verbo ser, Será [más linda] la vida, de los cuales 2 están en la voz pasiva, Si alguna vez fue amada. En 19 ejemplos, con el verbo estar, Eso está [malo], de los cuales 11 son participio pasado usado como nombre adjetivo: Estoy [agradecido]. En 33 ejemplos, se usa el nombre adjetivo como caso modal con otros verbos: Me siento [preso]. En 10 de éstos, se usa el participio pasado Voy [pega'ó]. En 6 ejemplos se usa el n-adjetivo participio pasado como antecedente preposicional del n-sustantivo, Vine condenado a morir.

El participio pasado es usado como n-adjetivo en 23/85 ejemplos. Es de notar que en dos ejemplos, Tengo [el rostro vestido <de> amarillo] y Disfruta [un parque lleno <de $>$ niños], el participio realiza la doble función de ser adjetivo para el n-sustantivo y n-adjetivo antecedente del complemento con preposición.

En cuanto a los modificadores, el n-adjetivo en caso modal carece de ellos, excepto por el adverbio. En 15/85 ejemplos, el n-adjetivo recibe adverbio intensificador; se usan muy, más, tan, algo, qué y adverbios terminados en -mente. Eres [muy grande], Las palmas son [más altas], Se pone el rey [más engreído], Desde chiquitico fue [tan bonito], La vida es [algo dura], Estoy [solo], [inmensamente solo], (Estoy) [completamente descontrolada]. 'Qué' se usa como adverbio en 5/15 ejemplos, [Qué bueno] será, [Qué sabrosa] tú estás, [Qué cheverón], [Qué chévere], [Qué rico].

\subsection{Revisión del concepto de adjetivo}

El adjetivo es una categoría secundaria, que modifica exclusivamente al n-sustantivo núcleo del constituyente, concordando con él en género y número.

Encontramos 147 ejemplos de adjetivo.

\begin{tabular}{|l|l|l|}
\hline Cantidad del sustantivo & Calidad del sustantivo & Total Adjetivo \\
\hline $\begin{array}{l}45 \\
\begin{array}{l}\text { Único, otro/a/s, más, mucho/a, } \\
\text { todo/a, gran, grandes }\end{array}\end{array}$ & 102 & 147 \\
\hline
\end{tabular}

El adjetivo se refiere en 45 ejemplos a la cantidad del n-sustantivo de cosa, persona, espacio y tiempo: Se escapó [toda la felicidad], Nosotros es [mucha gente], [Todo el mundo]

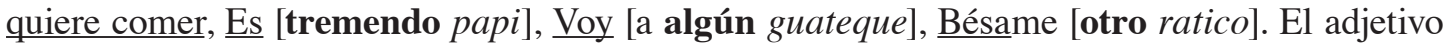
qué intensifica el n-sustantivo en dos ejemplos: [Qué cosa más grande] traigo yo, [Qué embale más bueno] traigo yo. Vez recibe modificadores de cantidad (la última, alguna, otra, cuántas, cada) y relativo, pero se refiere al tiempo del verbo y es invariable en género; es decir, mantiene su significación adverbial (Nebrija 1946: 85): Como si fuera esta noche [la última vez], Si [alguna vez] fue amada, [Otra vez] me sorprendo amando, [Cuántas veces] he intentado..., Se me acaba...[cada vez que] se aparece...].

En 102 ejemplos el adjetivo se refiere a la calidad del sustantivo núcleo del constituyente: [Este amor gitano] me devora, Pintaré [tu imagen linda], Me despierto [de ese rico sueño]. En 14/100, ejemplos aparece el participio pasado actuando como adjetivo, Tiene [amor escondido].

En cuanto a sus modificadores, la cualidad del adjetivo es intensificada por adverbio en 15 ejemplos. Se usan muy, más, tan, algo, bien y qué, Tiene [los ojos tan lindos], Fue [tan buena la nota que] dio..., Peco por querer [un amor tan divino], Disfruta [una música muy bella], Dame [un beso bien profundo], Quisiera componer [un verso bien sutil y dirigido], [Qué cosa más rica], [Qué embale más bueno], [Qué cosa más grande], [Qué rica mamita]. 
Cabe destacar que en dos ejemplos con 'lo', el adjetivo es modificador de que, No puedo entender [lo tonta que fui], [Todo lo malo que hiciste] lo pagarás.

\subsection{Presentación del concepto de nombre adverbio}

El nombre adverbio se refiere a las circunstancias en que ocurre la acción. En nuestro corpus, el n- adverbio se relaciona con el verbo como caso modal, caso cantidad, caso tiempo, caso espacio o se refiere a la modalidad de la oración, es decir, refleja la intención del hablante de afirmar, negar, dudar o condicionar, tema que será objeto de otro estudio. La principal característica del nombre adverbio y la que lo diferencia de otros nombres es que es invariable de hecho. No tiene desinencias femenina o masculina, singular o plural. Otra característica importante del nombre adverbio es que, como tal, no recibe otro modificador que el adverbio y el artículo neutro lo.

En el núcleo del constituyente adverbial, encontramos las variaciones n-adverbiosustantivo, n-adverbio-adjetivo, y n-adverbio propiamente. Las frecuencias son:

\begin{tabular}{|l|l|l|l|}
\hline $\begin{array}{l}\text { Nombre adverbio- } \\
\text { sustantivo }\end{array}$ & $\begin{array}{l}\text { Nombre adverbio- } \\
\text { adjetivo }\end{array}$ & Nombre adverbio & Total \\
\hline 4 & 9 & 153 & 166 \\
\hline
\end{tabular}

\subsubsection{El n-adverbio-sustantivo}

Los 4 ejemplos se encuentran en el caso cantidad y usan ya el artículo 'un' ya el artículo neutro 'lo' sin presentar desinencias, Toco [un poco], Te quiero [lo suficiente].

\subsubsection{El n-adverbio-adjetivo}

Se relaciona con el verbo como caso modal en 9 ejemplos. El nombre adjetivo comúnmente se refiere a la cualidad del nombre, pero en estos ejemplos hace referencia a la cualidad de la acción, oficio destinado al nombre adverbio. Es invariable como en los siguientes ejemplos, Sabe hacerme respirar [profundo], Tengo una pena que hiere [muy hondo], Cógelo [suave]. Cuando el n- adjetivo se usa en expresiones adverbiales, es decir, referidas al verbo, se vuelve invariable, [Poco a poco] me fui quedando sin respiración, Tratemos de arregla' [a las buenas], El mundo me quedó [al revés].

\subsubsection{El nombre adverbio núcleo del constituyente}

Nombre adverbio es la categoría que proponemos. Se relaciona con el verbo en 153 ejemplos, significativamente el más numeroso de los nombres estudiados. Los totales se presentan así:

\begin{tabular}{|c|c|c|c|c|}
\hline $\begin{array}{l}\text { Nombre adverbio } \\
\text { caso modal }\end{array}$ & $\begin{array}{l}\text { Nombre adverbio } \\
\text { caso cantidad }\end{array}$ & $\begin{array}{l}\text { Nombre adverbio } \\
\text { caso tiempo }\end{array}$ & $\begin{array}{l}\text { Nombre adverbio } \\
\text { caso espacio }\end{array}$ & Total \\
\hline $\begin{array}{l}\text { Nombre adverbio } \\
\text { caso modal }\end{array}$ & $\begin{array}{l}\text { más, mucho, tanto, } \\
\text { sólo (distribución) }\end{array}$ & $\begin{array}{l}\text { nunca, siempre, } \\
\text { ya, aún, todavía, } \\
\text { jamás, hoy, maña- } \\
\text { na, después, ahora, } \\
\text { entonces }\end{array}$ & $\begin{array}{l}\text { adelante, arriba, } \\
\text { allí, ahí, allá, aquí, } \\
\text { acá, atrás, cerca, } \\
\text { fuera }\end{array}$ & \\
\hline 25 & 24 & 72 & 32 & 153 \\
\hline
\end{tabular}


El n-adverbio se relaciona con el verbo como caso modal en 25 ejemplos: Mira [bien], Dímelo [así], Tú [también] me gustas, de los cuales, sólo dos son con ser: Así eres tú. Este hecho contrasta con el uso del n-adjetivo como caso modal donde 33/85 se hacen con ser.

El n-adverbio se relaciona con el verbo como caso cantidad, en 24 ejemplos: No me $\underline{\text { martirices }[m a ́ s], ~ P a r a ~ q u e ~ s u f r a s ~[m u c h o], ~[T a n t o] ~ t i e n e s ~[c u a n t o] ~ v a l e s, ~[S o ́ l o ~<e n>~ t i] ~ m e ~}$ hundo de amor (este sólo denota cantidad, no modo).

El n-adverbio se relaciona con el verbo como caso tiempo en 72 ejemplos, constituyéndose en la relación más común: [Nunca] me ha faltado nada, [Siempre] has dicho, [Ya] me voy, [Hoy] lo sé, [Ahora] estoy aquí. Diferenciamos entre n-sustantivo y n-adverbio para algunas ocurrencias en que nombres de tiempo, mañana, tarde, noche, día, hora, reciben las funciones y los modificadores del sustantivo. Si es agente o paciente cosa de la acción, y si recibe determinantes, lo consideramos n-sustantivo: Bendito es tu ayer, bendito es tu ahora., ...para cantarte [por la mañana], [La mañana] iba de gris, mañana. Si es tiempo de la acción y no recibe determinantes es nombre adverbio, Yo [mañana mismo] me caso.

El n-adverbio se relaciona con el verbo como caso espacio en 32 ejemplos: [Allí] te pongo una casita, [Aquí] estoy yo, El tiempo lo dejó [atrás].

En cuanto a sus modificadores, lo más común es que el n-adverbio aparezca solo; en 5/153 ejemplos recibe modificación adverbial, [Muy bien], [Nada más] se oye este cantar (nada, adv; más, nadv), No le importó de verme solo, [así llorando] (aquí el verbal gerundio como n-adverbio), [Ahora sí <que> no] puedo vivir sin ellos yo, Me siento de ti [más cerca].

El n-adverbio es introducido por preposición en los casos tiempo (2) y espacio (8), Llega [de tarde]; Mira [hacia arriba]. Las expresiones adverbiales, es decir, aquellas que se refieren a las circunstancias del verbo, generalmente son introducidas por preposición: de modo, Se aleja [de repente]; de tiempo, [En cuanto] bailó conmigo.

\subsection{Revisión del concepto de adverbio}

El adverbio es una categoría secundaria cuando se refiere al n-sustantivo, al n-adjetivo o al n-adverbio. Es una categoría terciaria cuando modifica al adjetivo o al adverbio. Encontramos 73 ejemplos de adverbio en nuestro corpus, 57 en función secundaria, 16 en función terciaria.

\begin{tabular}{|c|c|c|c|c|}
\hline Adverbio & $\begin{array}{l}\text { Secundario- } \\
\text { modificador } \\
\text { del nombre } \\
\text { sustantivo }\end{array}$ & $\begin{array}{l}\text { Secundario- } \\
\text { modificador del } \\
\text { nombre adjetivo }\end{array}$ & $\begin{array}{l}\text { Secundario- } \\
\text { modificador del } \\
\text { nombre adverbio }\end{array}$ & $\begin{array}{l}\text { Terciario- } \\
\text { modificador } \\
\text { del adjetivo }\end{array}$ \\
\hline Advmente & $\begin{array}{l}\text { solamente, sólo, } \\
\text { únicamente }\end{array}$ & $\begin{array}{l}\text { completamente, } \\
\text { inmensamente }\end{array}$ & & \\
\hline Modo & así, como, sí & así, como & así, como, mismo, sí & \\
\hline Cantidad & también, más & $\begin{array}{l}\text { más, tan, tal, muy, } \\
\text { algo }\end{array}$ & nada, no, muy & más, tan, muy \\
\hline Intensidad & & qué & sí & bien \\
\hline Lugar & Donde & & & \\
\hline $\begin{array}{l}\text { Totales } \\
\text { (73) }\end{array}$ & 31 & 15 & 11 & 16 \\
\hline
\end{tabular}

A través de la gramática centrada en el verbo, hemos descubierto que el adverbio también modifica al n-sustantivo como categoría secundaria, hecho no registrado en la 
literatura estudiada. Los adverbios sólo, solamente, únicamente, también, se refieren a la cantidad del nombre sustantivo de manera distributiva en 6 ejemplos: [Solamente tú] tienes asilo, [Sólo mi madre] me comprende a mí. En cuatro ejemplos, Me iba a dar [un nietecito así $<$ como $>$ Ray Donahue], el adverbio se refiere a la cualidad del sustantivo. En dos ejemplos, se usa el adverbio 'si', [Eso sí <que> no] [lo] hago, [A que sí] [le] dijo [el gato] <que> [yo] [te] voy a sacar. En un ejemplo, donde es usado como adverbio de lugar: Ibas de viaje [donde tus viejos del alma]. En 17 ejemplos, como es usado como adverbio comparativo, introduciendo el nombre sustantivo: Rojitas son [como el corazón].

$\mathrm{El}$ adverbio como categoría secundaria se refiere a la cantidad del nombre adjetivo en 15 ejemplos de diversas maneras: Estoy [completamente descontrolada]; El buey la tiene [muy dura]; Las palmas son [más altas]; Fue [tan bonito]; La vida es [algo dura]; [Qué sabrosa] tú estás. Para denotar la cantidad del nombre adjetivo encontramos un ejemplo en que el adverbio se adjetiva, es decir varía en género, La comida llega [toda junta].

El adverbio como categoría secundaria se refiere a la cantidad y calidad del nombre adverbio en sus diferentes relaciones de caso con el verbo en 11 ejemplos: en el caso tiempo, [Mañana mismo] me caso; en el caso modal, Tengo [una pena que] hiere [muy hondo] (hondamente), No le importó de verme [así llorando de amor].

El adverbio es una categoría terciaria cuando intensifica el adjetivo o el adverbio. Encontramos 16 ejemplos de este uso del adverbio en nuestro corpus: Te regalo [el beso más profundo]. Curiosamente, sólo en un ejemplo el adverbio se refiere en nuestro corpus directamente a otro adverbio, [No más <porque] me enamoro] se ponen a dar querella, no es adverbio de negación para el adverbio más. Podemos pensar en ejemplos como mucho más lejos, muy bien hecho.

\section{Conclusiones y recomendaciones}

Los 494 ejemplos de usos de las categorías sintácticas nombre adjetivo y nombre adverbio (núcleos del constituyente), y de las categorías morfológicas, adjetivo y adverbio (modificadores del núcleo del constituyente) encontrados en el material fueron susceptibles de análisis y explicación usando el marco teórico propuesto, la gramática centrada en el verbo, respetando los principios hjelsmlevianos de coherencia y simplicidad. La capacidad explicativa de este análisis se manifiesta en la manera elegante como revela las diferencias y semejanzas entre los diversos tipos de nombres que acompañan al verbo, y entre los modificadores de los nombres.

El nombre sustantivo núcleo del constituyente (incluyendo los pronombres) establece con el verbo todas las posibles relaciones de caso.

El nombre adjetivo comparte con el nombre sustantivo las relaciones de caso vocativo, agente persona y paciente cosa y persona. En estos casos, el nombre adjetivo recibe los determinantes del nombre sustantivo, más el artículo neutro 'lo'. Es por esto que lo llamamos nombre-adjetivo-sustantivo. Algunos ejemplos incluyen: [La gorda] va bailando (agente persona), Es [un bombón] (paciente cosa), Nada es útil [para esta inútil] (paciente persona). El nombre adjetivo propiamente comparte con el nombre adverbio la relación de caso modal. En esta instancia, el nombre adjetivo se diferencia del nombre adverbio en que siempre se refiere a un nombre sustantivo, con el cual concuerda en género y número: Eres [bendito], [Qué bueno] será, El baile está [bueno]. De los 85 ejemplos encontrados, 52 se realizan con ser o estar, verbos en que, como sabemos, agente y modal se refieren al mismo objeto de la realidad. 
El nombre adverbio, categoría que proponemos, realiza las relaciones de caso modal: Dímelo [así], cantidad, No me martirices [más], tiempo, [Nunca] me ha faltado nada, y espacio, [Allí] te pongo una casita, las cuales comparte con el nombre sustantivo. Con el nombre adjetivo, comparte la relación de caso modal. En esta instancia, a diferencia del nombre adjetivo, el nombre adverbio se refiere directamente al verbo y de tal manera es invariable. Este compartir la relación de caso modal, hace que el nombre adjetivo se use como nombre adverbio, hecho ampliamente estudiado en la literatura (Álvarez-Martínez 1986; Carbonero Cano 1971, Garcés Ma. Pilar 2001).

El paradigma de una gramática donde el verbo es considerado la categoría esencial, una gramática centrada en el verbo, precisa el metalenguaje morfo-sintáctico así:

Los nombres son una categoría primaria y pueden ser:

Nombre sustantivo o pronombre, La mujer que tengo, se ha puesto celosa, Yo soy

Nombre adjetivo-sustantivo, La suerte de la fea, la bonita la desea

Nombre adjetivo, Me siento preso

Nombre adverbio-adjetivo, Sabe hacerme respirar profundo

Nombre adverbio, Vivo bien

Los modificadores de los nombres son una categoría secundaria y pueden ser:

Adjetivo, cualidad, (fruta fresca), o cantidad del nombre sustantivo, (cuatro paredes).

Adverbio, cantidad y calidad del nombre sustantivo (únicamente tú eres...; me iba a dar un nietecito así), del nombre adjetivo, (estoy completamente descontrolada), y del nombre adverbio, (se oye muy bien).

El adverbio modificador de modificadores es una categoría terciaria que se refiere e intensifica al adjetivo, [una persona más normal], y al adverbio (No más porque me enamoro).

Algunas preguntas que nos gustaría aproximar en el futuro aplicando este marco teórico: ¿Cuál es el carácter sintáctico de las formas no-conjugadas del verbo?, ¿son los llamados adverbios demostrativos los pronombres del nombre adverbio?, ¿son los llamados adverbios relativos los pronombres relativos del nombre adverbio?, ¿cómo se usa el nombre adverbio para expresar la modalidad?

\section{Notas}

1. El signo + en la fórmula indica relación de caso con el verbo. La x es el número de relaciones de caso del verbo. Los verbos y verbales siempre están subrayados en el análisis. Los paréntesis ( ) indican carácter tácito. El signo igual = indica equivalencia.

2. Preferimos usar una abreviación del concepto de 'derivado verbal' de Bello (156), que la denominación de 'verboide' de Lenz, la cual suena despectiva.

\section{Bibliografía}

Alarcos Llorach, E. 1973. Estudios de Gramática Funcional del Español. Madrid: Gredos.

Álvarez Martínez, Ma. Á. 1986. "Sustantivo, adjetivo y adverbio: Caracterización funcional”. Verba. 13: 143-161. 
Bach y R. Harms. (eds). Universals in Linguistic Theory. New York: Holt, Rinehart and Winston.

Bello, Andrés. y R. J. Cuervo. 1964. Gramática de la Lengua Castellana. (7 ${ }^{\mathrm{ma}}$ ed). Buenos Aires: Sopena.

Bloomfield, L. 1933. Language. New York: H. Holt \& Co.

Bosque, Ignacio y Violeta Demonte. 1999. Gramática Descriptiva de la Lengua Española. Madrid: Espasa.

Carbonero Cano, Pedro. 1978. "Criterios para una caracterización funcional de los adverbios”. Revista española de lingüística. 8: 169-198

Corrales-Martin, Norma. 2004 [2006]. Gramática Viva. Ann Arbor: Xanedu.

2008. "Categorización de los enlaces españoles a través de la gramática verbal, una gramática centrada en el verbo". Cauce, Revista Internacional de Filología y su Didáctica. Universidad de Sevilla. 31: 103-119.

Cuadrado, Luis A. 1999. “Caracterización del adjetivo en la GRAE, el Esbozo y la Gramática de E. Alarcos Llorach”. Boletín de la RAE. 79: 407-423.

DRAE: Real Academia Española: Diccionario de la lengua Española. Versión Web. http:// buscon.rae.es/diccionario/drae.htm

Fillmore, C. 1968. “The Case for Case”. En: Bach y R. Harms. (eds), 1-90.

1971. "Some Problems for Case Grammar". Working Papers in Linguistics. 10: 245265.

Garcés, Ma. P. 2001. “Caracterización de los adjetivos en función adverbial en Español”. Lengua española y estructuras gramaticales. 141-153.

García Tejera, Ma. del Carmen. 1984. "El adverbio en la tradición gramatical española". Gades. 12: 183-206.

Gil y Gaya, S. 1968. Curso Superior de Sintaxis Española. La Habana: Pueblo y Educación.

Gutiérrez Ordoñez, Salvador. 1997. La Oración y sus Funciones. Madrid: Arco Libros.

Hjelmslev, L. 1976. Principios de Gramática General. Madrid: Gredos.

Hockett, C. 1971. Curso de Lingüística Moderna. Buenos Aires: Editorial Universitaria. 
Joos, Martin (ed). 1958. Readings in Linguistics New York: American Council of Learned Societies.

Kovacci, Ofelia. 1986. Estudios de Gramática Española. Buenos Aires: Librería Hachette.

Nebrija, A. 1492 [1946]. Gramática Castellana. Madrid: Edición de la Junta del Centenario.

Real Academia Española. 1973. Esbozo de una Nueva Gramática de la Lengua Española. Madrid: Espasa-Calpe.

Wells, R. 1958. “Immediate Constituents”. En: Martin Joos (ed.), 186-207. 